\title{
Aborted episode of sudden death due to delayed heart block after transcatheter aortic valve insertion
}

Kevin L. Greason, MD, Paul A. Friedman, MD, Daniel R. Brown, MD, PhD, and Verghese Mathew, MD, Rochester, Minn

Sudden cardiac death after transcatheter aortic valve insertion accounted for 22 of the $89(24.7 \%)$ cardiovascular deaths in the PARTNER Cohort $\mathrm{A}$ trial. ${ }^{1}$ We successfully resuscitated such a case caused by delayed complete heart block. The event prompted us to review our experience.

\section{BRIEF RESEARCH REPORT}

A 79-year-old woman presented with symptomatic severe aortic valve stenosis, multiple comorbidities, and a Society of Thoracic Surgeons predicted risk of mortality of $17.492 \%$. She had chronic atrial fibrillation with otherwise normal intraventricular conduction (Figure 1).

From the Mayo Clinic, Rochester, Minn

Disclosures: Authors have nothing to disclose with regard to commercial support.

Received for publication Sept 2, 2014; accepted for publication Sept 28, 2014;

available ahead of print Nov 14, 2014

Address for reprints: Kevin L. Greason, MD, Mayo Clinic, Rochester, MN 55905

(E-mail: greason.kevin@mayo.edu).

J Thorac Cardiovasc Surg 2015;149:639-40

$0022-5223 / \$ 36.00$

Copyright $(2015$ by The American Association for Thoracic Surgery

http://dx.doi.org/10.1016/j.jtcvs.2014.09.126
She underwent uneventful transfemoral transcatheter aortic valve insertion with a 26-mm SAPIEN XT valve (Edwards LifeSciences, Irvin, Calif). Her postoperative electrocardiogram was unchanged. She did well and was deemed stable for discharge on postoperative day 4. No skilled nursing facility bed was available, however, so the patient was kept in the hospital.

Two days later while ambulating in the hallway, the patient collapsed from sudden complete heart block with asystole. She was resuscitated with 2 minutes of cardiopulmonary resuscitation and inotropic medications. A rhythm of atrial fibrillation returned. There was no intraventricular conduction abnormality (Figure 2). The patient underwent emergency placement of a pacemaker. The case prompted an examination of our practice for other similar cases.

\section{METHODS}

Review of our SAPIEN transcatheter aortic valve insertion experience identified 396 patients operated from November 2008 to June 2014.

\section{RESULTS}

Of the 396 patients, $23(5.8 \%)$ received a pacemaker for postoperative heart block. The time from transcatheter valve

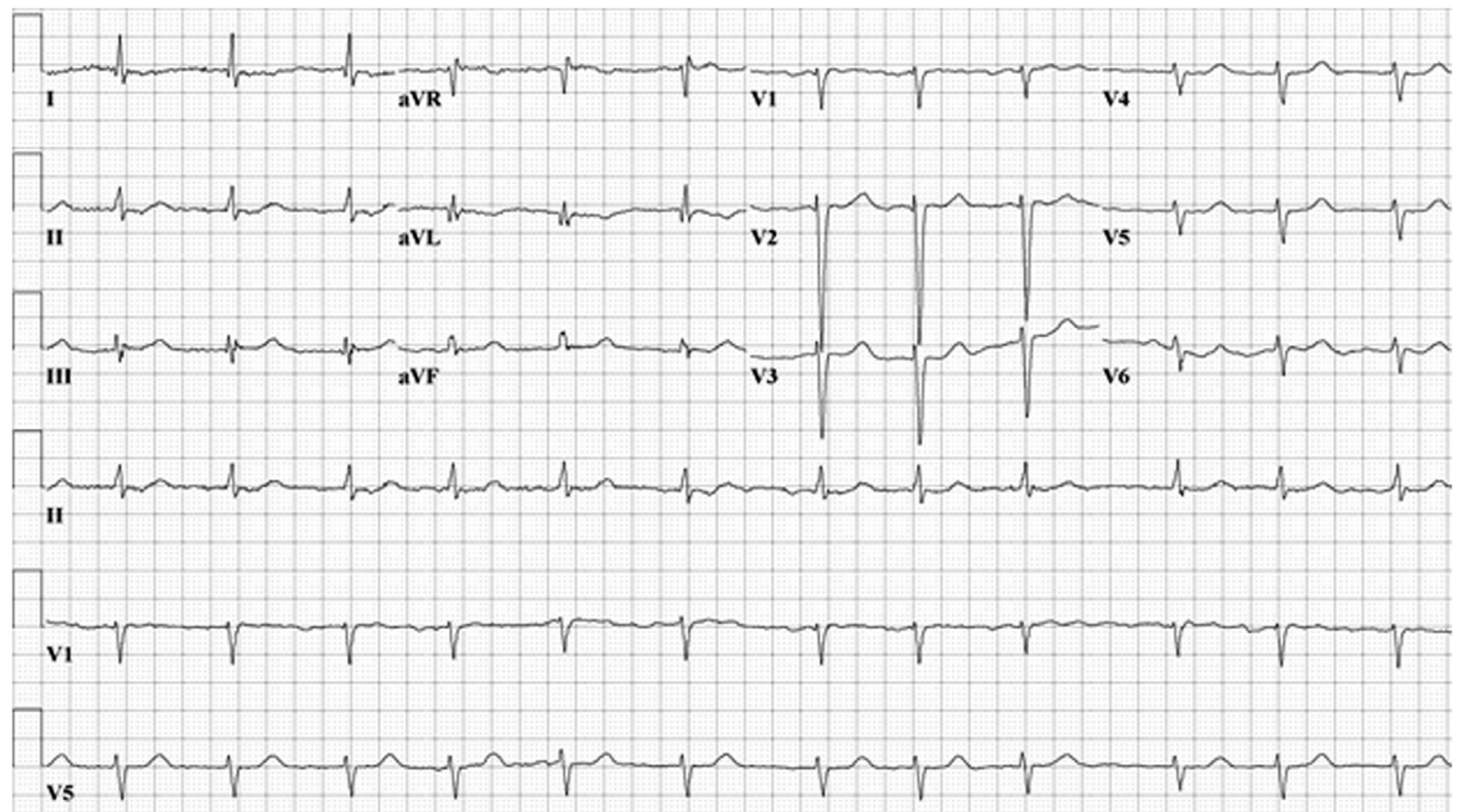

FIGURE 1. Electrocardiogram on admission. 


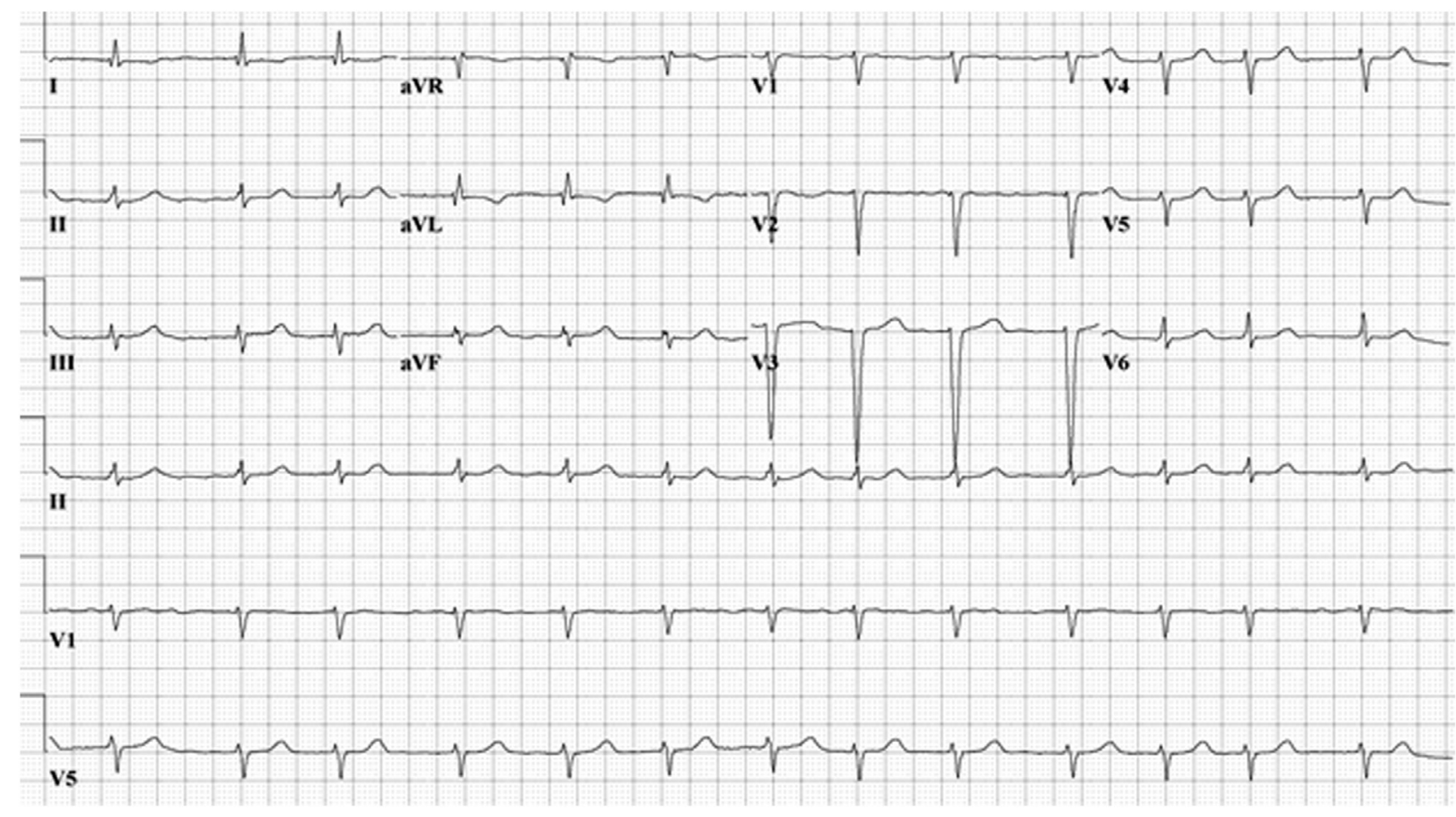

FIGURE 2. Electrocardiogram after cardiac arrest.

insertion to pacemaker placement was a median of 3 days (interquartile range, 2-5 days). In 1 patient discharged with sinus rhythm, heart block occurred 6 days after transcatheter valve insertion and 3 days after discharge from the hospital.

In-hospital mortality occurred in 14 of our 396 patients $(3.5 \%)$. An additional 4 patients $(1 \%)$ died after hospital discharge, but within 30 days of transcatheter valve insertion. In 3 of the 4 patients, the death was sudden. The 3 patients were discharged from the hospital 8,11, and 11 days after valve insertion, and death occurred 11,10 , and 11 days after discharge, respectively.

All 3 patients who died suddenly had intraventricular conduction abnormalities at discharge. One patient had chronic atrial fibrillation with chronic left anterior fascicular block + right bundle branch block; the second patient had new onset atrial fibrillation with new onset left bundle branch block; and, the third patient had normal sinus rhythm with chronic left bundle branch block.

\section{DISCUSSION}

There is a reported low, but definite, incidence of early sudden death after transcatheter aortic valve insertion. ${ }^{2,3}$
Initial review of the PARTNER trial data is that new onset left bundle branch block is not associated with the outcome. ${ }^{4}$ We report 5 cases, however, that raise the question of delayed heart block as a cause of sudden death. We encourage other groups to review their data for such cases. We propose a registry of routine mobile outpatient telemetry for diagnosis and intervention against this occurrence in all patients undergoing transcatheter aortic valve insertion.

\section{References}

1. Svensson LG, Blackstone EH, Rajeswaran J, Brozzi N, Leon MB, Smith CR, et al. Comprehensive analysis of mortality among patients undergoing TAVR: results of the PARTNER trial. $J$ Am Coll Cardiol. 2014;64:158-68.

2. Ferrari E, Namasivayam J, Marcucci C, Gronchi F, Berdajs D, Niclauss L, et al. Transapical aortic valve replacement in extreme-risk patients: outcome, risk factors and mid-term results. Eur $J$ Cardiothorac Surg. 2013;43:978-85.

3. Leon MB, Smith CR, Mack M, Miller DC, Moses JW, Svensson LG, et al. Transcatheter aortic-valve implantation for aortic stenosis in patients who cannot undergo surgery. N Engl J Med. 2010;363:1597-607.

4. Nazif TM, Williams MR, Hahn RT, Kapadia S, Babaliaros Y, Rodes-Cabau J, et al. Clinical implications of new-onset left bundle branch block after transcatheter aortic valve replacement: analysis of the PARTNER experience. Eur Heart J. 2014;35:1599-607. 